\title{
Effect of Heat Treatment on Magnetic Properties of Bulk Amorphous Alloys $\mathrm{Fe}_{63+x} \mathrm{Co}_{10} \mathrm{Y}_{7-x} \mathrm{~B}_{20}(\mathrm{X}=0,2)$
}

\author{
JERZY WYSLOCKI*, MATEUSZ TALAR \\ Institute of Physics, Faculty of Production Engineering and Materials Technology, Czestochowa University of Technology, \\ 19 Armii Krajowej Str., 42-200 Czestochowa, Poland
}

This paper presents the results of tests on amorphous alloys $\mathrm{Fe}_{65} \mathrm{CO}_{10} \mathrm{Y}_{5} \mathrm{~B}_{20} \mathrm{Fe}_{63} \mathrm{CO}_{10} \mathrm{Y}_{7} \mathrm{~B}_{20}$ in the state after solidification and after thermal treatment. The thermal treatment was performed below the crystallization temperature and above the Curie temperature $(750 \mathrm{~K} / 25 \mathrm{~min})$. The samples for the investigation had the shape of rods with a diameter of $1 \mathrm{~mm}$ and a length of $20 \mathrm{~mm}$. The structure and magnetic properties were studied for the research material. The structure was investigated using XRD and the magnetic properties using VSM and FERROTESTER. XRD studies showed that the samples both in solidified state and after thermal treatment had an amorphous structure. The losses for the re-magnetization of the tested samples were comparable to those for commercially used FeSi materials. The process of magnetization in the vicinity of the area called the approach to ferromagnetic saturation is associated with all tested samples with rotation of the magnetization vector near free volumes. An interesting result of the conducted research is that not always a thermal treatment made on general principles leads to improvement of magnetic

Keywords: bulk amorphous alloy, the total power loss, eddy current loss, H. Kronmuller theory

In materials engineering, modern materials with exceptional functional properties are still being sought for. Such materials include amorphous materials that have been tested for over 50 years [1]. Despite numerous studies on the amorphous structure and methods leading to obtaining amorphous materials, their nature is not fully known. Very interesting in terms of use are amorphous iron alloys (Mgs) [2-5]. They have very good mechanical properties, good corrosion resistance, exhibit good magnetic properties and are not too expensive to produce [6-7]. Depending on the chemical composition, they may exhibit high magnetization saturation (Ms), low losses on remagnetization $(P)$, low coercive field $(\mathrm{HC})$, which makes them an attractive material for use in various types of electrotechnical equipment [8]. The amorphous structure has no pattern as it is in the case of a crystalline structure. Therefore, it is difficult to evaluate and describe the properties of the material under investigation. Determining the properties requires a lot of research. The reason may be that the amorphous structure for different alloys may be formed in different ranges of the supercooled liquid region. In the volume of amorphous alloys, areas with different concentration of components may be formed, which implies different density. These areas may be called clusters or clusters of atoms. It is these clusters of atoms that affect the properties of amorphous materials. In the case of amorphous tapes (up to 100 (m thick) called conventional amorphous materials, the properties of samples taken from different areas are similar. However, in the case of massive amorphous materials (from 100 im), these properties differ significantly.This change is visible for areas coming from a different distance from the inlet of the mold in which the molten alloy solidifies [9]. In order to homogenize the solidified material, it is usually used to heat it. In amorphous materials, defects of the structure can be distinguished, which can be divided into free volumes and pseudolocation dipoles [10-12].These defects are examined using an indirect method based on the analysis of the primary magnetization curve carried out in accordance with the assumptions of $H$. Kronmüller's theory [10-12]. It has been shown in numerous works that the change in the shape of Ewing's knee gives the possibility to assess the impact of structural defects on magnetic properties [10-22].

The paper presents the results of investigations of structure and magnetic properties for bulk amorphous $\mathrm{Fe}_{65} \mathrm{CO}_{10} \mathrm{Y}_{5} \mathrm{~B}_{20^{\prime}} \mathrm{Fe}_{63} \mathrm{CO}_{10} \mathrm{Y}_{7} \mathrm{~B}_{20}$ alloys in the form of rods with a diameter of $1 \mathrm{~mm}$ and a length of about $20 \mathrm{~mm}$. It has been shown that thermal treatment performed according to the adopted scheme does not always lead to improvement of magnetic properties. It was also found that after isothermal annealing (750K / $25 \mathrm{~min}$ ) the magnetization process in the area of the approach to ferromagnetic saturation is associated with the same types of defects of the amorphous structure.

\section{Computational details}

The components for the production of the test material were purity: $\mathrm{Fe}-99.99 \%$ at.; Co $-99.98 \%$ at .; $\mathrm{Y}-99.98 \%$ at .; B - 99.99 at $\%$.. In the first stage the preparation of test material was prepared $10 \mathrm{~g}$ ingot. The ingots were then divided into smaller portions, which were used to produce supercooled samples. Samples of $\mathrm{Fe}_{65} \mathrm{CO}_{10} \mathrm{Y}_{5} \mathrm{~B}_{20}$ $\mathrm{Fe}_{63} \mathrm{CO}_{10} \mathrm{Y}_{3} \mathrm{~B}_{20}$ alloys in the form of rods $20 \mathrm{~mm}$ in length and $1 \mathrm{~mm}$ in diameter by means of liquid alloy suction methods for a water-cooled copper mold. Both ingots and rods were produced in an arc furnace (100 - 450A) in a protective atmosphere of argon. In both melting processes, pure titanium melted before melting, which served as an absorbent of the remaining impurities in the chamber. In the work, the samples were investigated in solidified state and after heat treatment were carried out in a vacuum oven at $750 \mathrm{~K}$ and annealing time of $25 \mathrm{~min}$.

A X-ray diffractometer from the BRUKER D8 ADVANCE company equipped with a cobalt lamp was used to study the structure. Structural investigations were carried out for powdered samples in the range of $2 \Theta$ angle from $30^{\circ}$ to $120^{\circ}\left(0.02^{\circ}\right.$ measuring step, measuring time per $5 \mathrm{~s}$ step $)$.

* email: wyslocki@wip.pcz.pl 
Magnetization measurements were made using a vibration magnetometer working in a magnetic field with an intensity of up to $2 \mathrm{~T}$. These measurements were made for open samples in the form of rods with a diameter of 1 $\mathrm{mm}$ and a length of $5 \mathrm{~mm}$. During the analysis of the magnetization curves, the demagnetizing field was taken into account.The internal magnetic field $\mu_{0} \vec{H}$ ij is the vector sum of the external field applied to the sample $\mu_{0} \vec{H}_{z e w}$ of the anisotropy field $\mu_{0} \vec{H}_{z e w}$ and the demagnetizing field $\mu_{0} \vec{H}_{o d}$ :

$$
\mu_{0} \overrightarrow{\mathrm{H}}_{\text {ef }}=\mu_{0} \overrightarrow{\mathrm{H}}_{z e w}+\mu_{0} \overrightarrow{\mathrm{H}}_{\mathrm{A}}+\mu_{0} \overrightarrow{\mathrm{H}}_{\mathrm{dd}}
$$

Due to the small value of the anisotropy field for further calculations, they were neglected. Taking this into account, the internal magnetic field can be determined from the formula:

$$
\mu_{0} H_{e f}=\mu_{0} H_{z e w}-\mu_{0} H_{o d},
$$

where: $\mathrm{H}_{\text {od }}=\mathrm{N}_{\text {od }} \cdot M$,

$\mathrm{N}_{\text {od }}$ - dedmagnetization factor,

$M$ od - magnetization.

Taking into account that the tested samples had the shape of bars while calculating their demagnetisation coefficient $\mathrm{N}_{\text {od }}$ the dependence was used:

$$
N_{o d}=5,5(m-0,54)^{-1,4}, m<10,
$$

where $m$ is the ratio of the length to the diameter of the rod [23].

On the basis of the analysis of the curves of the primary magnetization curve, which was carried out in accordance with the assumptions of $\mathrm{H}$. Kronmüller's theory called the approach to ferromagnetic saturation, the type of defects of the amorphous structure and the areas of their influence in the magnetization process were determined [10-12].In higher magnetic fields, where the process of magnetization is no longer affected by the defects of the amorphous structure, the range corresponding to the Holstein-Primakoff paraproces was determined [24]. The total core losses were measured using the automated FEROTESTER system operating in the 50 - $1000 \mathrm{~Hz}$ frequency range.

\section{Results and discussions}

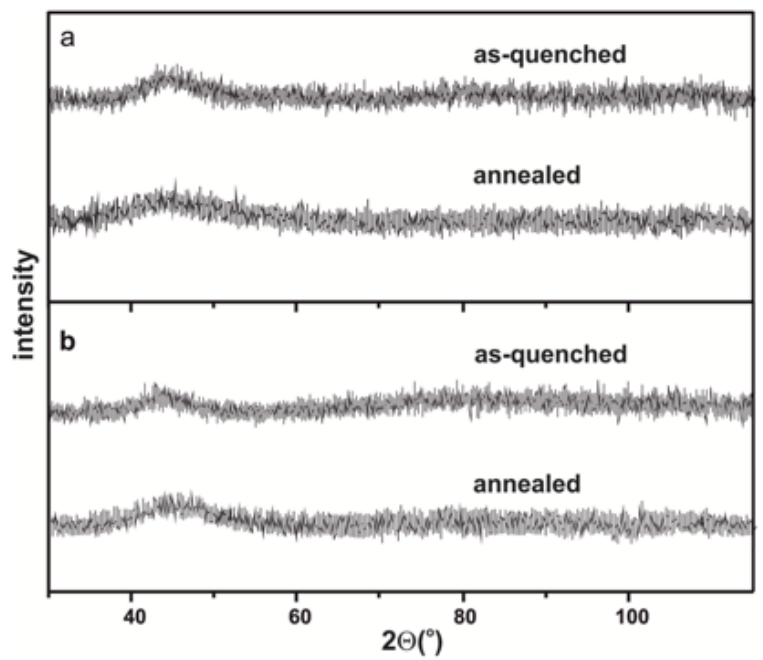

Fig. 1. X-ray diffraction images for bulk amorphous $\mathrm{Fe}_{65} \mathrm{CO}_{10} \mathrm{Y}_{5} \mathrm{~B}_{20}$ (a) alloys, $\mathrm{Fe}_{63} \mathrm{CO}_{10} \mathrm{Y}_{7} \mathrm{~B}_{20}$ (b) in as quenched state $[25,26]$ and after isothermal annealing

Figure 1 shows X-ray diffraction pattern obtained for the investigated samples in the state after solidification and after heat treatment.

Analyzing the obtained X-ray diffraction patterns for the tested samples, both in the state after solidification and after isothermal annealing at $750 \mathrm{~K} / 25 \mathrm{~min}$, one can notice a single wide maximum occurring near the angle of $2 \theta=$ $44^{\circ}$. Such a maximum is typical for amorphous alloys formed on the basis of iron. These results indicate that the structure of the tested samples is characterized by a lack of volumetric periodicity in the arrangement of atoms, and atoms interact with each other for short distances without preserving angular translations. The lack of crystallographic planes from which $X$-rays are reflected in accordance with the Bragg law, giving clear rings is the reason for the creation of a wide diffuse maximum in $\mathrm{X}$-ray diffraction images.

Figure 2 shows the dependence of magnetic susceptibility on the amplitude of the magnetizing field
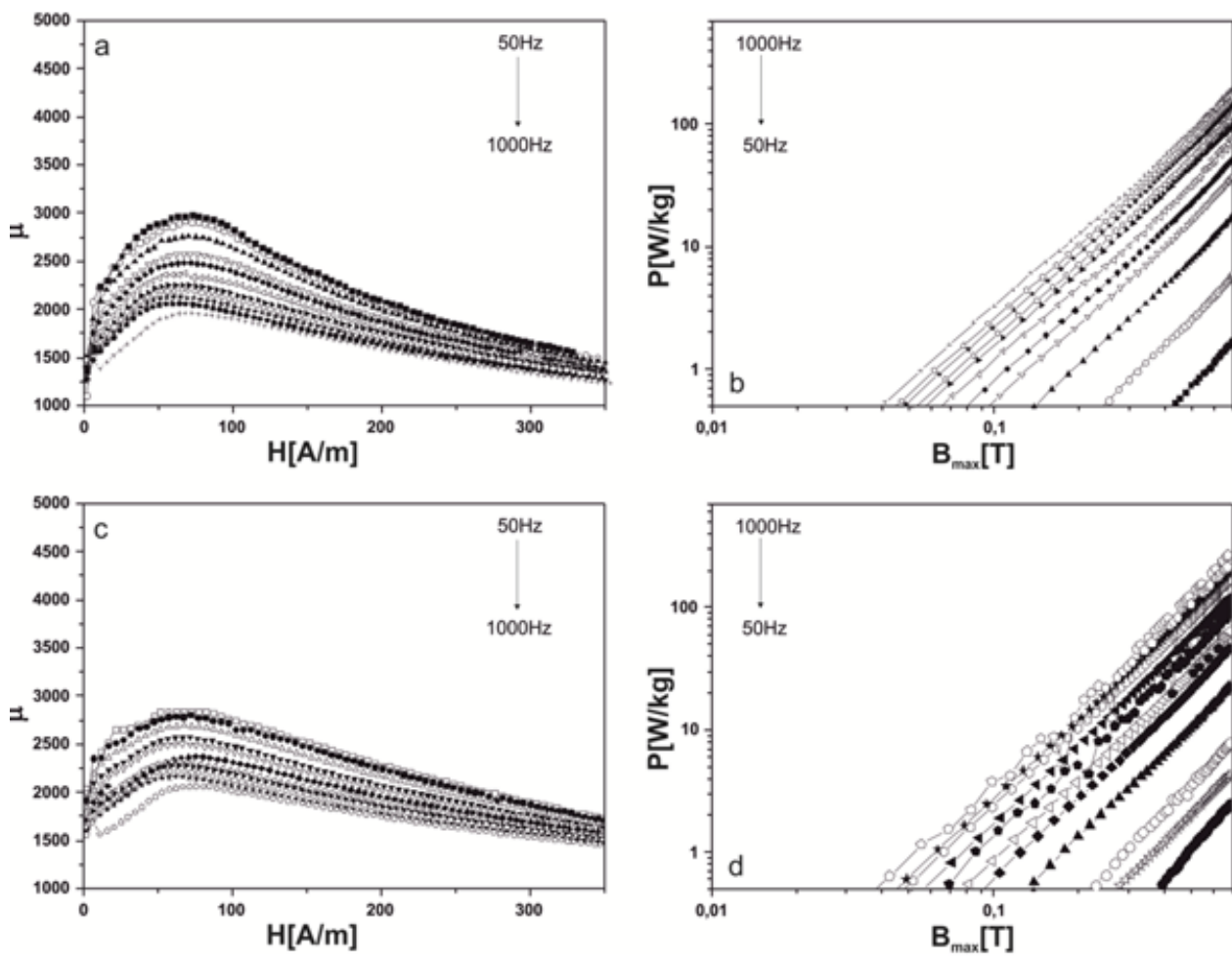

REV.CHIM. (Bucharest) $70 \bullet$ No. 2 \2019

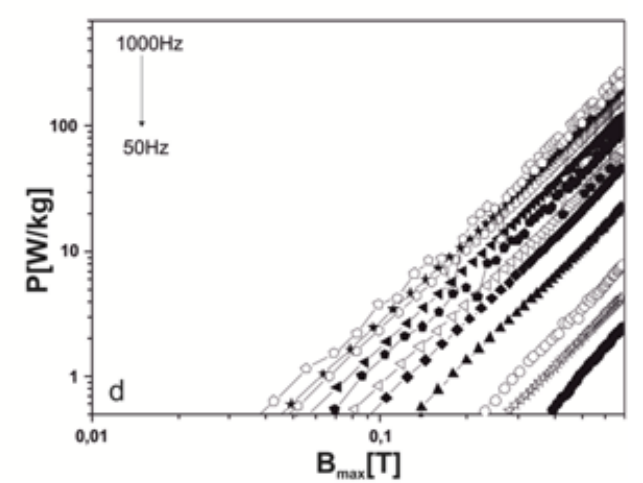

http://www.revistadechimie.ro
Fig. 2. The dependence of magnetic susceptibility on the amplitude of the magnetizing field $(a, c)$ and total core losses as a function of the maximum induction $(b, d)$ for the bulk amorphous alloy $\mathrm{Fe}_{65} \mathrm{CO}_{10} \mathrm{Y}_{5} \mathrm{~B}_{20^{\prime}}$ in the state after solidification $(\mathrm{a}, \mathrm{b})$ [25] and after isothermal annealing $(c, d)$ 
$(2 \mathrm{a}, 2 \mathrm{~b})$ and the total core losses as a function of the maximum induction $(2 b, 2 d)$ for the massive amorphous $\mathrm{Fe}_{65} \mathrm{CO}_{10} \mathrm{Y}_{5} \mathrm{~B}_{20}$ alloy, in the as-quenched state $(2 \mathrm{a}, 2 \mathrm{~b})$ and after isothermal annealing $(2 \mathrm{c}), 2 \mathrm{~d}$ ).

Figure 3 shows the dependence of magnetic susceptibility on the amplitude of the magnetizing field $(3 a, 3 c)$. Furthermore, the total core losses in the function of the maximum induction for the bulk amorphous $\mathrm{Fe}_{63} \mathrm{CO}_{10} \mathrm{Y}_{7} \mathrm{~B}_{20}$ alloy are presented (3b, 3d).

As can be seen in figure $2 a$ and $3 a$, magnetic permeability at $50 \mathrm{~Hz}$ for a solidified sample of $\mathrm{Fe}_{65} \mathrm{CO}_{10} \mathrm{Y}_{5} \mathrm{~B}_{20}$ alloy is about 3000, while for the second alloy $\mathrm{Fe}_{63} \mathrm{CO}_{01} \mathrm{C}_{20} \mathrm{~B}_{20}$ about 4,800 .As the frequency increases, a reduction in the maximum of magnetic susceptibility is observed. It should also be added that the increase in the amplitude of the magnetizing field is the reason for the gradual decrease of magnetic susceptibility. The shape of the magnetic susceptibility curves as a function of the amplitude of the magnetizing field after the thermal treatment is similar to that of the samples after solidification. However, it should be noted that the magnetic susceptibility for samples of tested alloys after thermal treatment decreased slightly. This phenomenon may be related to the decomposition of the amorphous state. In the case of the investigated alloys both in the solidified state and after the isothermal process of $750 \mathrm{~K} / 25 \mathrm{~min}$, the value of total core losses as a function of the maximum induction is comparable with the loss value characteristic of classical Fe-Si alloys. The total core losses as a function of the square of the magnetizing field frequency for both investigated alloys are shown on figure 4.

In figure 4, for each of the curves we can observe an increase in total losses along with the square of the frequency of the magnetizing field. The non-linear relationship $P\left(f^{2}\right)$ is evidence of additional losses in the sample. They can be result from one or more processes and are associated with magnetic delay. This delay may be caused inter alia the diffusion of interstitial atoms or by thermal fluctuations. These fluctuations in soft magnetic materials can allow passage of the domain wall through the energy barrier. It should be noted that the total losses for re-magnetization are much lower for the $\mathrm{Fe}_{63} \mathrm{CO}_{10} \mathrm{Y}_{7} \mathrm{~B}_{20}$ alloy. This means that the introduction of an additional $2 \%$ at. $Y$ in the place of Fe affects the reduction of core losses. It is known that yttrium has a large atomic radius (180 $\mu \mathrm{m})$ and has effects on the improvement the improvement of the glass transition ability of $\mathrm{FeCOB}$ alloys [27], while Fe, Co and B have atomic radii $135 \mu \mathrm{m}, 140 \mu \mathrm{m}$ and $80 \mu \mathrm{m}$, respectively. This choice of alloying elements is in accordance with the criteria adopted by A. Inoue [28]. The increase in the amount of $Y$ most likely affects the nonuniform redistribution of alloy elements in volume, i.e. the formation of areas of different density. This pattern of amorphous structure formation may be the reason for both improvement and deterioration of magnetic properties. In the case of $\mathrm{Fe}_{65} \mathrm{CO}_{10} \mathrm{Y}_{5} \mathrm{~B}_{20}$ alloy, the behavior of the total
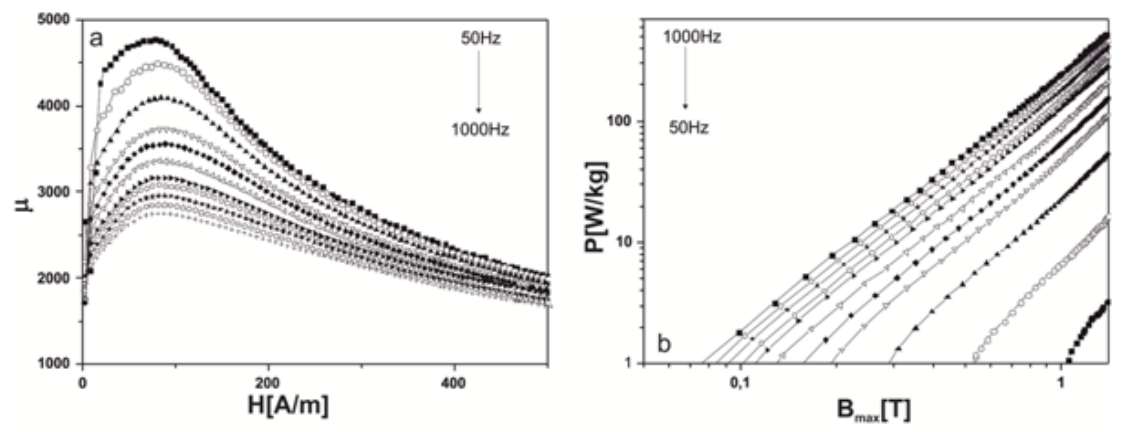

Fig. 3. The dependence of magnetic susceptibility on the amplitude of the magnetizing field $(a, c)$ and total core losses as a function of the maximum induction $(b, d)$ for the
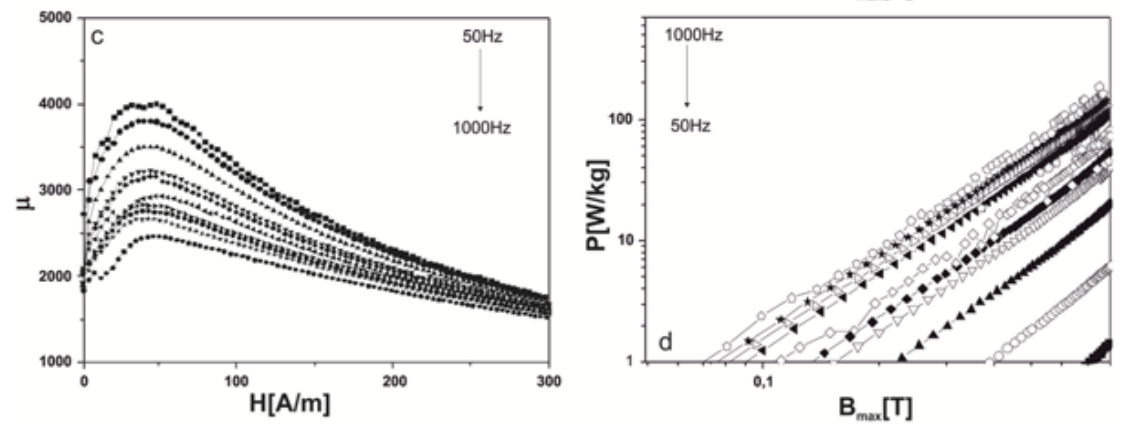
bulk amorphous alloy $\mathrm{Fe}_{63} \mathrm{Co}_{10} \mathrm{Y}_{7} \mathrm{~B}_{20}$, in solid state $(a, b)[25]$ and after isothermal annealing $(c, d)$

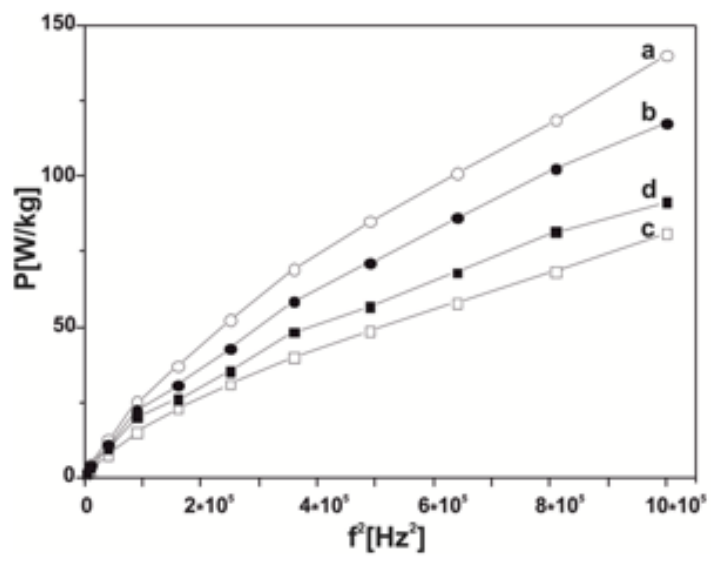

Fig. 4. Total core losses a function of the square of the magnetizing field frequency for the tested alloys: $\mathrm{Fe}_{65} \mathrm{CO}_{10} \mathrm{Y}_{5} \mathrm{~B}_{20}$ in the state after solidification (a) [25] and after heat treatment (b), and $\mathrm{Fe}_{63} \mathrm{CO}_{10} \mathrm{Y}_{7} \mathrm{~B}_{20}$ in the state after solidification (c) [25] and after heat treatment $(\mathrm{d})$, for a maximum induction equal to $0.6 \mathrm{~T}$. 

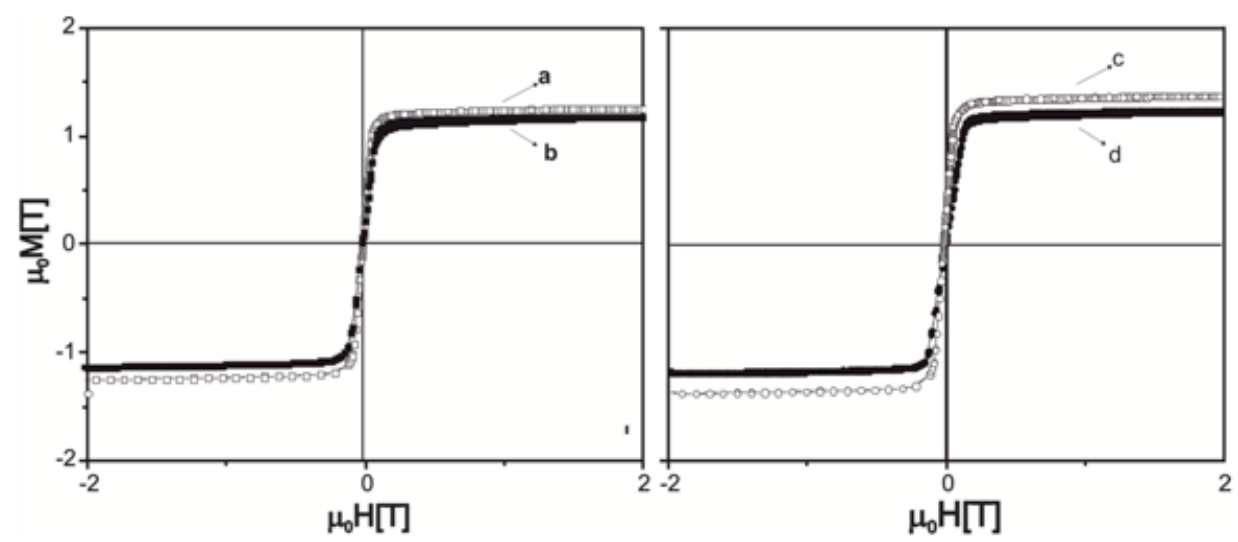

$\mu_{0} \mathrm{H}[\mathrm{T}]$
Fig. 5. Static hysteresis loops recorded or the investigated alloys: $\mathrm{Fe}_{65} \mathrm{Co}_{10} \mathrm{Y}_{5} \mathrm{~B}_{20}$ in the state after solidification (a) [26] and after heat treatment (b), and $\mathrm{Fe}_{63} \mathrm{CO}_{10} \mathrm{Y}_{7} \mathrm{~B}_{20}$ in the state after solidification (c) [26] and after heat treatment (d) losses before and after heating requires no comment. On the other hand, for the second of the investigated alloys, the total losses for re-magnetization as a function of the square frequency for the sample after heating have a higher value than in the state after solidification. It should be noted that the amorphous structure can be formed in a wide range of subcooled liquid. Therefore, itis possible to obtain an amorphous structure with a highly diversified structure in terms of the distribution of elements and the size of atomic aggregates. This statement may explain the abnormal behavior of total losses to the demagnetization of the alloy with a higher $Y$ content. In the volume of the alloy there are areas with different content of components. These areas can be a fraction of a cubic nanometer or fill a significant part of the material. For the magnetic material the course of losses for re-magnetization is closely related to the domain structure, and specifically to the free movement of domain walls in the volume of the material. When the domain wall encounters an obstacle, its movement slows down, because it requires more energy. This causes an increase of core losses in the material. In this particular case, in the sample after solidification, small areas could be formed with different similar compositions, preceded by a matrix constituting the front for the atom jump between these regions. As a result of isothermal heating, the supplied energy cause the migration of atoms. This leads to enlarging the areas that are the composition fluctuations. Therefore, it can be assumed that in the sample after heating the inhomogeneous areas were so large that the movement of domain walls occurred for higher energies than in the samples after solidification. An important technical parameter of magnetic materials is their saturation magnetization. By means of a vibration magnetometer, static hysteresis loops (fig. 5) were recorded, which have a typical shape as in the case of magnetic materials exhibiting so-called magnetically soft properties. On the basis of the static hysteresis loops analysis it was found that the heat treatment for both tested alloys caused a decrease in saturation magnetization (fig. $5 b$, 5d), i.e. for $\mathrm{Fe}_{65} \mathrm{Co}_{10} \mathrm{Y}_{5} \mathrm{~B}_{20}$ alloy from 1.37 T to 1.24 T, and for $\mathrm{Fe}_{63} \mathrm{CO}_{10} \mathrm{Y}_{7} \mathrm{~B}_{20}$ alloy from 1.25 $\mathrm{T}$ to $1.17 \mathrm{~T}$. This magnetization behavior confirms that the annealing process below the crystallization temperature and above the Curie temperature does not always lead to an improvement in the magnetic properties.

Based on the analysis of the initial magnetization curves according to the theory of $\mathrm{H}$. Kronmuller, in the area called the approach to ferromagnetic saturation, the types of defects of the structure and their influence on the magnetization process of the obtained alloys were determined.

Figure 6 presents high - field magnetisation curves $M / M_{s}\left(\left(\mu_{0} H\right)^{-1 / 2}\right)(a, c)$ and $M_{s}\left(\left(\mu_{0} H\right)^{1 / 2}\right)(b, d)$ for the
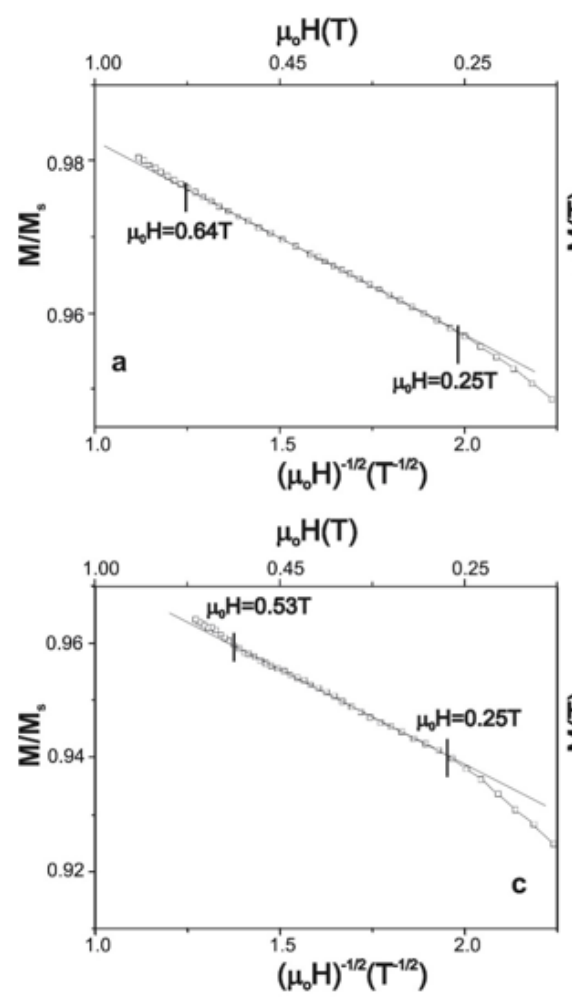

REV.CHIM.(Bucharest) $70 \bullet$ No. 2 \2019
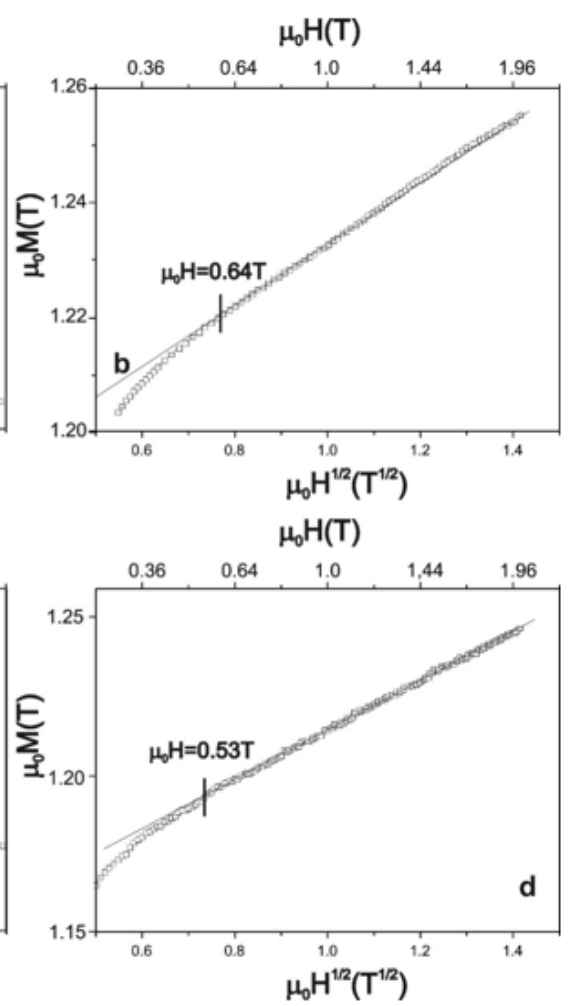

http://www.revistadechimie.ro
Fig. 6. High-field magnetisation curves $M / M_{s}\left(\left(\mu_{0} H\right)^{-1 / 2}\right), M_{s}\left(\left(\mu_{0} H\right)^{1 / 2}\right)$ for the alloy $\mathrm{Fe}_{65} \mathrm{CO}_{10} \mathrm{Y}_{5} \mathrm{~B}_{20}$ in the state after solidification $(\mathrm{a}, \mathrm{b})$

[26] and after heat treatment ( $c, d)$ 

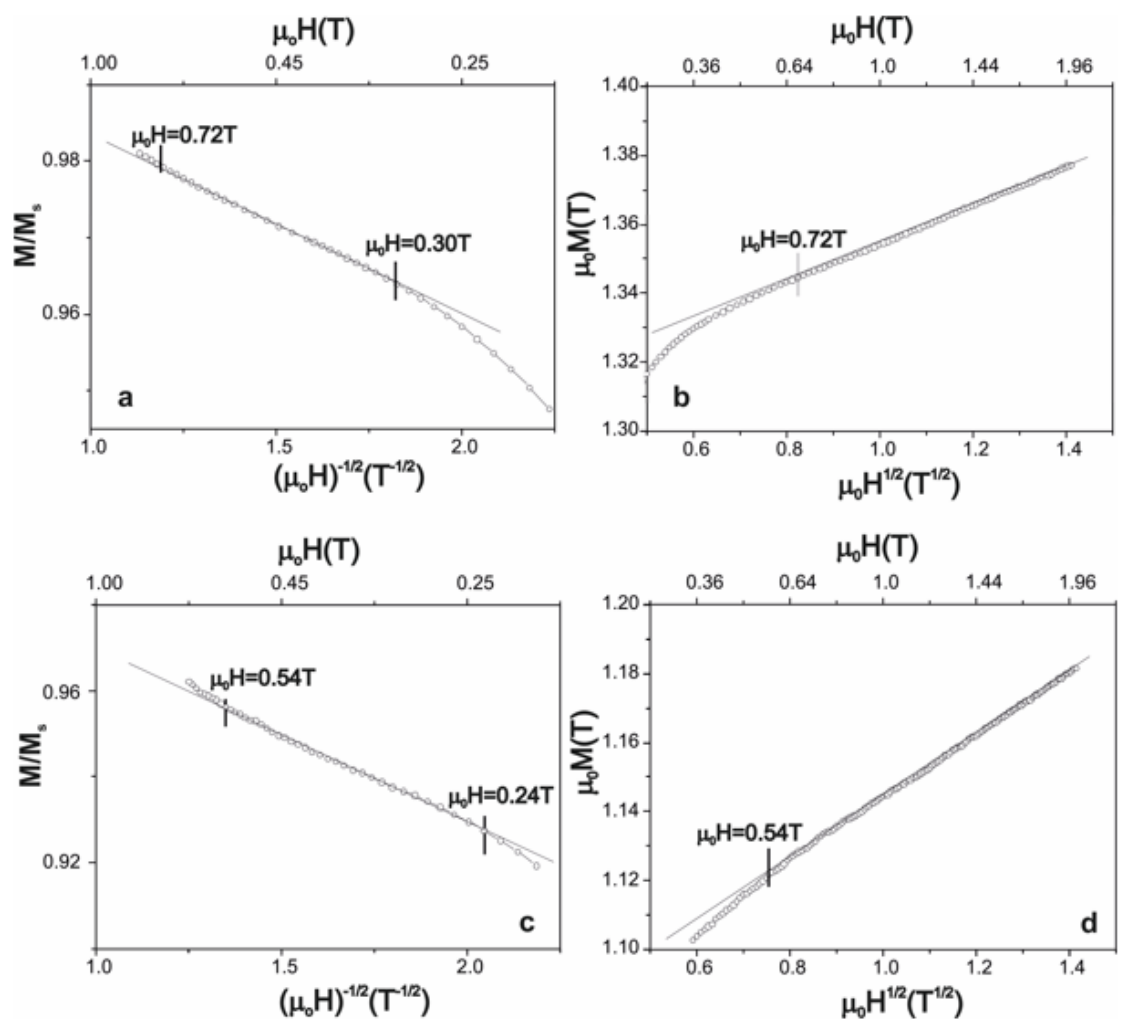

Fig. 7. High-field magnetisation curves $M / M_{s}\left(\left(\mu_{0} H\right)^{-1 / 2}\right), \operatorname{Ms}\left(\left(\mu_{0} H\right)^{1 / 2}\right)$ for alloy $\mathrm{Fe}_{63} \mathrm{Co}_{10} \mathrm{Y}_{7} \mathrm{~B}_{20}$ in solid state $(\mathrm{a}, \mathrm{b})[26]$ and after heat treatment $(c, d)$
alloyFe ${ }_{65} \mathrm{CO}_{10} \mathrm{Y}_{5} \mathrm{~B}_{20}$ in the state after solidification and after heat treatment.

The linear relationship of reduced magnetization as a function of $\left(\left(\mu_{0} \mathrm{H}\right)^{-1 / 2}\right)$ for the sample after solidification and after annealing is observed. For a sample in solidified state, this relationship occurs in the range of field from $0.25 \mathrm{~T}$ to $0.64 \mathrm{~T}$, and after isothermal heating - from $0.25 \mathrm{~T}$ to $0.53 \mathrm{~T}$. This means that, within this magnetic field range,the magnetization pro cess is connected with small rotations of the magnetic moments in the vicinity of point defects. In stronger magnetic fields, of greater than $0.64 \mathrm{~T}$ and $0.53 \mathrm{~T}$ for the samples in the as-quenched and annealed states, respectively, the slightincrease in the magnetization is caused by the Holstein-Primakoff paraproces. This process is connected with damping of thermally-induced spin waves.

For the second investigated alloy - $\mathrm{Fe}_{63} \mathrm{CO}_{10} \mathrm{Y}_{7} \mathrm{~B}_{20}$, similar relationships were observed (fig.7).

In the case of the $\mathrm{Fe}_{63} \mathrm{CO}_{10} \mathrm{Y}_{7} \mathrm{~B}_{20}$ alloy, also the point defects have a decisive influence on the magnetisation process (in the fields from $0.30 \mathrm{~T}$ to $0.72 \mathrm{~T}$ for the sample after solidification and from $0.24 \mathrm{~T}$ to $0.48 \mathrm{~T}$ for the sample after isothermal heating). The linear dependence of $M_{s}\left(\left(\mu_{0} H\right)^{1 / 2}\right)$ indicates the occurrence of the HolsteinPrimakoff paraprocess [24].

\section{Conclusions}

The structure of alloys after solidification and after isothermal heating at $750 \mathrm{~K} / 25 \mathrm{~min}$ was investigated using an X-ray diffractometer. Based on the obtained results, it was found that the alloy structure is an amorphous structure In a stronger magnetic field (i.e. greater than $0.4 H_{c}$ ), during the magnetization process of the alloy, irreversible processes take place, and magnetic hysteresis is observed. The area of the hysteresis loop is a measure of the losses associated with magnetization and de-magnetization [2931]. Based on the research, it was found, the investigated sample has higher core losses than classic amorphous ribbons, which is related to its lower electric resistance. Lower electrical resistance value is related to thickness of the investigated material. This leads to higher losses on eddy currents. It was also found that in addition to losses caused by magnetic hysteresis and eddy currents, there are also additional losses during the magnetization of alloys. Additional losses are mainly related to relaxation caused by atomic migration. Comparing the loss values for samples after solidification and after annealing, we can conclude a slight reduction in losses for the $\mathrm{Fe}_{65} \mathrm{CO}_{10} \mathrm{Y}_{5} \mathrm{~B}_{20}$ alloy. In the case of the second alloy, a slight increase in losses is observed. On the basis of magnetic studies, it was found that the magnetic permeability for the $\mathrm{Fe}_{65} \mathrm{CO}_{1} \mathrm{Y}_{5} \mathrm{~B}_{3}$ alloy is about 3000, while for the second of the tested alloys, i.e. $\mathrm{Fe}_{63} \mathrm{CO}_{10} \mathrm{Y}_{7} \mathrm{~B}_{20}$, it is about 4800. After the isothermal annealing process of the tested alloys, a slight reduction of magnetic susceptibility was observed. This may be related to the decomposition of the amorphous state.

Using the vibration magnetometer (VSM), static hysteresis loops were recorded. Itwas fond, that the shape of the registered loops is typical for magnetic materials exhibiting magnetically soft properties. Saturation magnetization for the tested alloys was also determined (1.37 T for the $\mathrm{Fe}_{65} \mathrm{Co}_{10} \mathrm{Y}_{5} \mathrm{~B}_{20}$ alloy and $1.25 \mathrm{~T}$ for the $\mathrm{Fe}_{63} \mathrm{CO}_{10} \mathrm{Y} \mathrm{B2}_{0}$ alloy)... In adddition, it was found that the heat treatment of investigated materials resulted in a reduction of these values.

The investigation of the 'magnetisation in the area close to ferromagnetic saturation' showed that, the magnetisation process in strong magnetic fields for both investigated alloy is connected with rotation of the magnetic moments in the vicinity of the point defects, and the damping of the thermally-induced spin waves by the magnetic field (Holstein-Primakoff paraproces)

\section{References}

1.INOUE, A., Mater. Sci. Fundations 6 (1998) TRANSTECH PUBLICATIONS 2.GENG, Y., WANG, Y., QIANG, J., ZHANG, G., DONG, C., HAUSSLER, P., J. Non- Cryst. Solids432, 2016, p. 453

3.SI, J., MEI, J., WANG, R., CHEN, X., HUI, X., Mater. Lett. 181, 2016, p. 282

4.INOUE, A., SHINOHARA, Y., GOOK, J., Mater. Trans. JIM 36, 1995, p. 427

5.SHEN, B., AKIBA, M., INOUE, A., Appel. Phys. Lett. 88, 2006, 131907 
6.KASHIMOTO, K., Appl. Surf. Sci. 257, 2011, p. 8141

7.MCHENRY, M. E., WILLARD, M. A., LAUGHLIN, D. E., Prog. Mater. Sci. 44, 1999, p. 291

8.ZHANG, J. H., CHANG, C. T., WANG, A. D., SHEN, B. L., J. Non Cryst. Solids 358, 2012, p. 1443

9.NABIALEK, M., J. Alloys Comp. 642, 2015, p. 98

10.KRONMULLER, H., IEEE Trans. Magn. 15 (5), 1979, p. 1218

11.KRONMULLER, H., J. URNEL,J. Magn. Magn. Mater.6 (C), 1977, p. 52

12.KRONMULLER, H., J. App. Phys. 52 (3), 1981, p. 1859

13.MINCIUNA, M.G., VIZUREANU, P., ACHITEI, D.C., GHIBAN, B., SANDU, A.V., MARECI, D., BÃLAN, A., Rev. Chim (Bucharest) 65, no. 10, 2014, p 1138.

14.ACHITEI, D.C., VIZUREANU, P., DANA, D., CIMPOESU, N., Metalurgia International, 18, SI2, 2013, p. 104.

15.PERJU, M.C., GALUSCA, D.G., NEJ NERU, C., LARGEANU, A.E., Metalurgia International, 15, no. 11, 2010, p. 41.

16.ACHITEI, D.C., VIZUREANU, P., MINCIUNA, M.G., SANDU, A.V., BUZAIANU, A., DANA, D.I., Mat. Plast., 52, no. 2, 2015, p. 165.

17.J EZ, B., NABIALEK, M., GRUSZKA, K., PIETRUSIEWICZ, P., JEZ, K., RZACKI, J., SZOTA, M., BLOCH, K., GONDRO, J., European J ournal of Materials Science and Engineering, 2, no. 2-3, 2017, p. 57.

18.BINDEA, M., CHEZAN, C.M., PUSKAS, A., Journal of Applied Engineering Sciences, 5, no. 1, 2015, p. 7.

19.CIUCA, I., BOLCU, A., STANESCU, M.M., Environmental Engineering And Management J ournal, 16, no. 12, 2017, p. 2851.
20.IONESCU, D., MATASARU, D., RADU, V., University Politehnica of Bucharest Scientific Bulletin-Series A-Applied Mathematics And Physics, 75, no. 4, 2013, p. 265.

21.DANDU-BIBIRE, L., BORSOS, Z., MATASARU, D., CASIAN-BOTEZ, I., NICULESCU, A., AGOP, M., University Politehnica of Bucharest Scientific Bulletin-Series A-Applied Mathematics And Physics, 73, no. 2, 2011, p. 175.

22.GHEORGHE, D., SCHWARTZ, M., CIUCA, I., CIOCOIU, R., Mat. Plast., 55, no. 3, 2018, p. 454.

23.SHIRAKAWA, Y., J. J apan Inst. Metals 21, 1957, p. 294

24.HOLSTEIN, T., H. PRIMAKOFF, Phys. Rev. 58 (12), 1940, p. 1098 25.BLOCH, K., TITU, M. A., SANDU, A. V., Rev. Chim. (Bucharest), 68, no. 9,2017, p.2162

26.BLOCH, K., Rev. Chim. (Bucharest) 69, no. 4, 2018, p.982A.

27.LU, Z.P., LIU, C.T., PORTER, W.D., App. Phys. Let. 83 (13), 2002 , p. 2581

28.INOUE, A., Mater. Sci. Eng.A 226-228, 1997, p. 357

29.PICCIN, R., TIBERTO, P., CHIRIAC, H., BARICCO, M., J. Phys. 144 2009, p. 012073

30.BARBISIO, E., FIORILLO, F., RAGUSA, C., IEEE Trans. Magn. 40, 2004, p. 1810

31.SHEN, T.D., XIN, S.W., SUN, B.R., J. Alloy. Compd. 658, 2016, p. 703

Manuscript received: 15.07 .2018 